\title{
Research on the Cost of Human Resources of Colleges Based on Performance Assessment
}

\author{
Juan Huang*, Rui Du, Xiaohua Hou \\ Shaanxi Institute of International Trade \& Commerce, Xi’an, 712046, China \\ *Corresponding Author: Juan Huang
}

Keywords: Performance assessment, Performance evaluation, Cost of human resources.

\begin{abstract}
With human society entering the era of knowledge economy, human resources have become the most important resources to promote social development. It is very important to improve the performance management of human resources in colleges, which are the human resource intensive organizations. This paper analyzes the composition and common problems of human resource cost in colleges, and gives some countermeasures and suggestions from the aspects of fair evaluation of performance, improvement of management efficiency and optimization of promotion system to provide some references for the relevant researchers.
\end{abstract}

\section{Introduction}

At present, the management information technology both at home and abroad has already made certain achievements, and this has also promoted the development of human resources and information technology. In this widespread information management technology, teacher performance appraisal model in human resource management has gradually been widely used and recognized by colleges and universities. In the process of development, some achievements have been made in the development of performance appraisal of teachers in the management of human resources in Colleges and universities. This is not conducive to the innovation of the teacher performance appraisal model in the process of human resource management. In the process of establishing university teachers' performance evaluation model of human resource management exist some obstacles, how to change the disadvantages of the establishment of teacher performance evaluation model of human resource management in colleges and universities for advantage, become an important problem. With the increasing influence of teacher performance appraisal model on the construction of human resource management in colleges and universities, human resources management has attracted more and more people's attention. However, these concerns have not mentioned the corresponding solutions to the present problems, and the problems in the construction of the teacher performance appraisal model in the establishment of human resources management in universities still exist. In practice, from the standpoint of feasibility, we must use quantitative methods to manage. To get rid of the dilemma, most schools will focus on Reform of the salary system and management system construction, and to effectively run through the effective compensation system to protect the personnel management system, to achieve the overall goal of the school. The establishment of a fair performance appraisal system, the effective combination of limited human, financial and material resources, and the promotion of the construction of teaching staff are the problems that must be solved in regulating the operation mechanism and strengthening the management of colleges and universities.

\section{Composition of Cost of Human Resources of Colleges}

Human resource cost is paid to obtain and develop human resources must be the price, it should normally include a series of fees paid in the personnel recruitment, recruitment and selection, 
arrangement, use, orientation and on-the-job training and a series of process. The cost of human resources of university teachers is the price that colleges and universities pay for teachers' human resources to achieve their work goals and development goals. But the cost of teachers in Colleges and universities is based on education, not on the output of products or services. The cost of human resources in Colleges and universities is the total expenditure incurred by the University to obtain, maintain and develop human resources. It mainly consists of the following parts: acquisition cost, maintenance cost and development cost. Acquisition cost refers to the expenses incurred by a school to obtain a certain human resource, including recruitment, selection, expenditure. Maintenance cost refers to the regular expenses incurred by the school during the employment of employees, including wages, benefits and so on. Development cost refers to the expenses incurred by the school to improve the quality of staff, including training, training expenses. The performance salary is also known as performance related wages or salary is based on performance, according to the task and work performance distribution of teachers' salary, job performance and job performance evaluation and compensation to establish a system of association. It aims to distinguish between mediocrity and excellence in work and motivate teachers to pursue outstanding work outcomes. Salary is determined by performance, which is different from the general bonus or bonus. It is generally reflected in salary increase, not temporary. Performance pay, along with job promotion and tenure, is linked to an assessment of job performance. Pay for performance as part of post-performance salary system, which belongs to the category of maintenance cost, pay more attention to the assessment of the cost of human resources investment effect, which is based on the employee's performance and contribution to change the feedback, pay for performance, to achieve the employee reward or punishment.

\section{Common Problems of Cost of Human Resources of Colleges}

Too High Cost of Human Resources of Colleges. Training is an effective way to promote the construction of teaching staff in Colleges and universities and to improve the professional quality of teachers. It is conducive to the realization of the strategic objectives of colleges and universities. At present, most of the high-quality training in our universities choose the backbone teachers of each profession. At the same time, affected by funding, time, and geography, in many schools, opportunities for training are only available among professional teachers with large numbers of students. Differential treatment is conducive to improving the level of teaching staff, and the widening gap is not conducive to the unity of the teachers. During training, both the form and the level are insufficient, and the training of the higher intellectuals emphasizes more and more in-depth knowledge structure and system. College recruitment usually has a strict and detailed requirement for the qualifications and diplomas of the applicants, and adopts the combination of written examination and interview. In the process, it meets the requirements of higher education recruitment. But the recruitment of candidates in the professional, there is no specific targeted requirements. Specialize in teaching work in Colleges and universities, people should have this ability, high comprehensive quality of people a lot of time is not suitable for academic work, teachers' energy is limited. In the spirit of strong professionalism, higher education should teach and educate people, so teachers should be so demanding.

Irrational Structure of Human Resources of Colleges. The core of performance pay is that teachers' pay level varies with individual and team performance. In this system, according to the university paid is to show the teacher through the efforts to achieve the school has the value of output in the work process, the culture and the value of the match with the school's view, and is conducive to the realization of the strategic goal of school behavior. Therefore, the performance appraisal salary and the post allowance have different emphases. Relatively speaking, post allowance provides basic protection, while performance compensation focuses on motivation. When teachers' performance can be evaluated fairly and received corresponding remuneration, the teachers' psychological needs for both sense of fairness and sense of achievement can be satisfied at the same time. The most important resources of colleges and universities are human resources, and the cost of human resources is the main aspect of educational cost. For a long time, the human resources as a public resource and is free 
to use, without considering the cost of colleges and universities in the use of human resources, to maximize the interests of the local conditions, this can easily lead to the expansion of the number of university teaching staff. Correlation is not the cost of human resources and financial performance. Human resources structure is not directly related to university teaching and research performance and human resources is related to the cost of teaching and scientific research work is the main work in Colleges and universities. The subjects of scientific research are teachers, especially those with high educational background. The demand for teachers with high professional titles is relatively large, which means that the cost of human resources should be increased and the human resources structure should be improved to improve the performance of scientific research institutions. On the other hand, if the human resources investment is not significant, the performance of its research institutions is not significant.

\section{Optimization Countermeasures of Cost of Human Resources of Colleges Based on Performance Assessment}

Fair Evaluation of Performance. University Teachers' income from the basic salary, allowance and performance evaluation of three parts, the basic salary of two parts of national unity rank wages, local subsidies, no fundamental difference between different universities, based on teachers' Professional Title Change and national unification plan changes. Post allowance, from inside the school registration duties allowance decision within the duration of the basic fixed, post allowance and professional titles and job level is directly related to, have great influence on Teachers' income and incentive effect. The basic salary of college teachers is stable, which is the guarantee factor of teachers. Post subsidies and performance appraisal salaries are affected by time and work performance, which have incentive effect on teachers. The core of performance pay system is the teachers' personal and team performance determine the salaries of teachers in this system, according to the value of the output of university teachers, job performance, cultural values and to achieve the strategic goal of school behavior pay wages to ensure the performance appraisal of teachers' performance can be a fair evaluation, meet the teachers' sense of fairness a sense of achievement and psychological needs. Establishment and implementation of the performance appraisal of college salary embodies the advantages of the following aspects. Raise the average income level of schools. To retain talented people with high productivity, and to leave the less productive mediocre teachers away. It reduces the phenomenon of part-time teachers, improves the morale of teachers, attracts outstanding research talents in other fields, and enters universities and colleges.

Improvement of Management Efficiency. Human resource is the most active resources, the cost of human resources is the core of education cost, long-term since human resources in Colleges and universities are regarded as public resources, resulting in the use of human resources while ignoring the cost of many colleges and universities have the problems of expansion of the number of staff. Control the cost of human resources should be carried out based on the fairness of salary and performance system, improve the efficiency of human resources, keep costs and create benefits directly, cannot think of the human resource cost as low as possible. If the human resource cost is lower than the corresponding quality of the staff salary levels, especially the performance lost wages incentive role for teachers, it will cause injury to staff's enthusiasm, resulting in the decline of work efficiency, is not conducive to the staff working potential, saving the cost of vested benefits impact. In order to stimulate the enthusiasm of staff and staff, it is necessary to establish a scientific and reasonable salary performance system, and combine it with human cost management, and gradually improve the level of human resources management in colleges and universities. Colleges and universities need to actively establish a more transparent and fair pay system, open rules, provide equal opportunities for competition, and fair distribution. Among the teachers frequently, if their investment returns and colleagues to find psychological balance, teachers will have the power to work, found not a fair place, will adversely affect their work enthusiasm. In addition, a fair environment to create a harmonious atmosphere is also of great help, contribute to the research work of scientific research, teaching, development, schools need to actively establish the classification 
evaluation system, segmentation evaluation index, to deal with the complex work of teachers in colleges and universities.

Optimization of Promotion System. Teacher career planning is one of the human resources departments, and it is also a reflection of the improvement of teachers' welfare. Vision incentive, to motivate employees, helps employees to set up their own professional goals consistent with their own and consistent with the school. Teacher positions are not frequently promoted and are mainly academic studies. Therefore, appropriate training can improve teachers' professional quality and promote their success in academic research. Teachers are the core part of human resource management, and the recruitment of teachers directly affects the quality and level of teaching. Therefore, the selection of teachers in Colleges and universities should be consistent with the strategy, in the teacher's demand, teachers selection basis form certain rules and regulations, do according to the recruitment process, scientific and reasonable selection method. The implementation of performance reform, so that staff attention to performance is far more than academic research, the establishment of academic intense mechanism, is conducive to encouraging the overall development of employees, to provide students with more academic knowledge. The level of employee benefits is affecting employee's sense of belonging and security to a certain extent. New ways should be adopted to improve the treatment of employees, enrich the spiritual needs of employees, and improve the enthusiasm of employees. Teacher's job description is the norm of teacher's behavior and the requirement of teacher's professional accomplishment. The teacher is the special worker, they work mainly is the outlook on life and values has not really formed in youth, therefore, teachers not only have sufficient professional knowledge, moral requirements are relatively high, teaching is not only in knowledge, is also reflected in the moral education. The teacher's words and actions have direct influence on the students and guide the students. A teacher's job description must be comprehensive and careful. Corporate culture can fundamentally influence employees' thinking and improve their work enthusiasm.

\section{Conclusion}

The implementation of performance appraisal system in Colleges and universities, strengthen the work of human resources management, need to give full consideration to the compensation performance occupy in the performance system in proportion, and the cost of human resources management work together, meet the individual teacher expectations, both college affordability and cost efficiency of human resources, to ensure the fairness of performance appraisal salary, gradually improve the management of human resources cost.

\section{References}

[1] Wang Xiaofeng. On Environment Analysis and Path Selection of College Teachers' Performance Evaluation [J]. Journal of Hunan University of Science \& Technology (Social Science Edition), 2012, 15(5): 178-180.

[2] Fang Yangchun. The effect of work stress and social support on college teachers job performance [J]. Science Research Management, 2013, 34(5): 136-143.

[3] Sun Lihua. Study on the Relationship between Strategic Human Resources Management and Innovation Performance - the Mediator of Corporate Culture [J]. International Business, 2016(6): 137-147.

[4] Jia Jianfeng, Wang Lu, Yan Jiaqi, Tang Guiyao. Exploring the Relationship between Teacher Competence of Research-oriented University and Job Performance- The Moderating Effect of Strength of Human Resource Management [J]. Soft Science, 2016, 30(11): 105-108. 